\title{
2010 Updated Assessment of Undiscovered Oil and Gas Resources of the National Petroleum Reserve in Alaska (NPRA)
}

Using a geology-based assessment methodology, the U.S. Geological Survey estimated mean volumes of 896 million barrels of oil $(M M B O)$ and about 53 trillion cubic feet (TCFG) of nonassociated natural gas in conventional, undiscovered accumulations within the National Petroleum Reserve in Alaska and adjacent State waters. The estimated volume of undiscovered oil is significantly lower than estimates released in 2002, owing primarily to recent exploration drilling that revealed an abrupt transition from oil to gas and reduced reservoir quality in the Alpine sandstone 15-20 miles west of the giant Alpine oil field.

\section{Introduction}

The National Petroleum Reserve in Alaska (NPRA) has been the focus of oil exploration during the past decade, stimulated by the mid-1990s discovery of the adjacent Alpine field - the largest onshore oil discovery in the United States during the past 25 years. Recent activities in NPRA, including extensive 3-D seismic surveys, six Federal lease sales totaling more than $\$ 250$ million in bonus bids, and completion of more than 30 exploration wells on Federal and Native lands, indicate in key formations more gas than oil and poorer reservoir quality than anticipated. In the absence of a gas pipeline from northern Alaska, exploration has waned and several petroleum companies have relinquished assets in the NPRA.

This fact sheet updates U.S. Geological Survey (USGS) estimates of undiscovered oil and gas in NPRA, based on publicly released information from exploration wells completed during the past decade and on the results of research that documents significant Cenozoic uplift and erosion in NPRA. The results included in this fact sheet-released in October 2010supersede those of a previous assessment completed by the USGS in 2002.

\section{Recent Exploration Drilling}

Most wells drilled during recent NPRA exploration, whose initial drilling season occurred in 2000, are within 50 miles of the Alpine oil field and targeted the Alpine sandstone, the main reservoir in Alpine field (fig. 1). The stratigraphic interval including the Alpine sandstone was assessed as the Beaufortian Upper Jurassic play in the USGS 2002 assessment of NPRA.

Five discoveries of oil have been reported in the Alpine sandstone in northeastern NPRA (fig. 2). Alpine West, Lookout, and Pioneer are oil accumulations with little or no free gas. A fourth discovery, Mitre, appears to be predominantly a gas accumulation with an oil leg in the south (fig. 2). The fifth discovery, the Spark-Rendezvous accumulation, is a much larger reservoir system that includes gas plus condensate at shallower depths in the north and oil at greater depths in the south (fig. 2).
Significantly, the Spark-Rendezvous accumulation represents an abrupt transition of hydrocarbon phase within the Alpine sandstone - from oil on the east to gas on the west. Most known or inferred hydrocarbon accumulations west of SparkRendezvous are gas. This transition occurs just 15 to 20 miles west of the Alpine oil field and is not related to the structural position of the reservoir (fig. 2). Tests of gas flow rates and volumes are not known to have been conducted west of the Spark-Rendezvous accumulation.

Although the data released are insufficient to make a precise calculation of the volume of oil and gas discovered, we estimate that 120 to $200 \mathrm{MMBO}$ (including oil and condensate) and 1.9 to 3.0 TCFG may be technically recoverable from these accumulations. The Spark-Rendezvous accumulation is so large that if it were entirely oil, it would rival or exceed the Alpine field in recoverable resources.

Several recently drilled wells, most located west and northwest from the Spark-Rendezvous accumulation, evaluated other stratigraphic intervals, including (from oldest to youngest) the Triassic Ivishak Sandstone (Ellesmerian Ivishak play in the USGS 2002 assessment of NPRA), lower Kingak Shale (Beaufortian Lower Jurassic Topset play), uppermost Kingak Shale (Beaufortian Cretaceous Topset play), and the Torok Formation (Brookian Clinoform play). One well in the Ellesmerian Ivishak play and two wells in the Beaufortian Cretaceous Topset play are dry holes. At least four wells in the Beaufortian Lower Jurassic Topset play encountered gas shows but no indications of recoverable oil. Two wells in the Brookian Clinoform play encountered oil-saturated sandstone with poor reservoir quality and were not tested (fig. 2; Kokoda). Also, two wells (Spark 4 and Hunter; fig. 2) that targeted the Alpine sandstone encountered thin intervals of oil-saturated sandstone in the Brookian Topset play. Seven wells drilled west of Spark-Rendezvous remain proprietary (figs. 1 and 2); we infer that these are either gas shows or dry holes based on the predominance of gas in wells lower on structure, relinquished leases, and company divestiture of assets.

In southeastern NPRA, one recently drilled well at the Wolf Creek gas accumulation (discovered in 1951) remains 


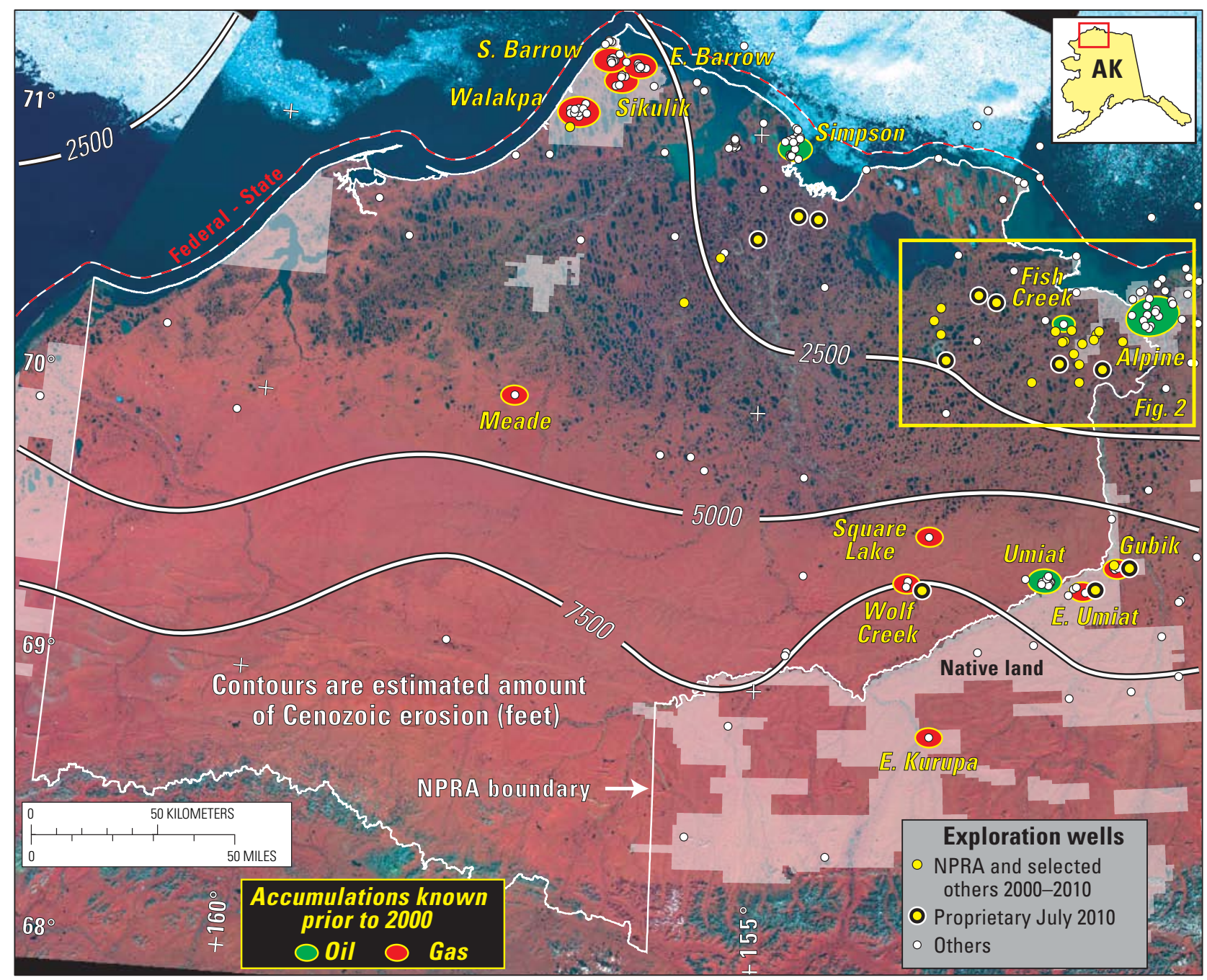

Figure 1. National Petroleum Reserve in Alaska (NPRA; boundary shown by white line) with locations of exploration wells, oil and gas accumulations known prior to 2000 (names in yellow; all too small to be economically viable except Alpine), and Native lands. Total area assessed includes NPRA and adjacent State waters. White contours indicate amount of Cenozoic exhumation (in feet) estimated by analysis of sonic logs from exploration wells (source: http://pubs.usgs.gov/pp/pp1732/ pp1732d/. Yellow rectangle is area shown in figure 2. Map base is a false-color composite Landsat image.

proprietary. Just outside the southeastern boundary of NPRA, two wells were drilled recently at the Gubik gas accumulation (discovered in 1963) and another well, located near the East Umiat gas accumulation (discovered in 1964), was drilled to a deeper target. One of the recent Gubik wells indicates producible gas. The other recent Gubik well and the deeper test at East Umiat remain proprietary. These wells drilled in the Brooks Range foothills add no information to indicate the need for updating the 2002 USGS assessment of plays in southern NPRA.

\section{Cenozoic Uplift in NPRA}

Cenozoic uplift and erosion (from about 60 to 15 million years ago) of the Brooks Range foothills in southern NPRA and of a broad area in northern NPRA (fig. 1) may provide an explanation for the unanticipated predominance of gas in the Alpine sandstone and other strata. The magnitude and timing of uplift and erosion have been estimated by using sonic logs from exploration wells (fig. 1) and additional geological evidence. The uplift and erosion caused a decrease in confining pressure on subsurface fluids, resulting in expansion of free gas in reservoirs, degassing of oil in reservoirs, and degassing of formation water.

Oil generation and most gas generation were complete across NPRA by about 90 million years ago. Thus, at the time of Cenozoic uplift and erosion, it is likely that oil was present in various reservoirs in northern NPRA (lower thermal maturity) and that gas was present in various reservoirs in southern NPRA (higher thermal maturity). In areas of modest uplift in northeastern NPRA, degassing of oil accumulations likely generated gas caps and displaced oil downward into poorer quality reservoir rocks (for example, Spark-Rendezvous). In areas of moderate uplift in northwestern NPRA and significant uplift in southern NPRA, degassing of oil combined with significant gas expansion likely caused a gas "flush" outward, away from the uplifted areas. Oil degassing and gas expansion likely explain the abrupt oil-to-gas transition in the Alpine sandstone in northeastern 


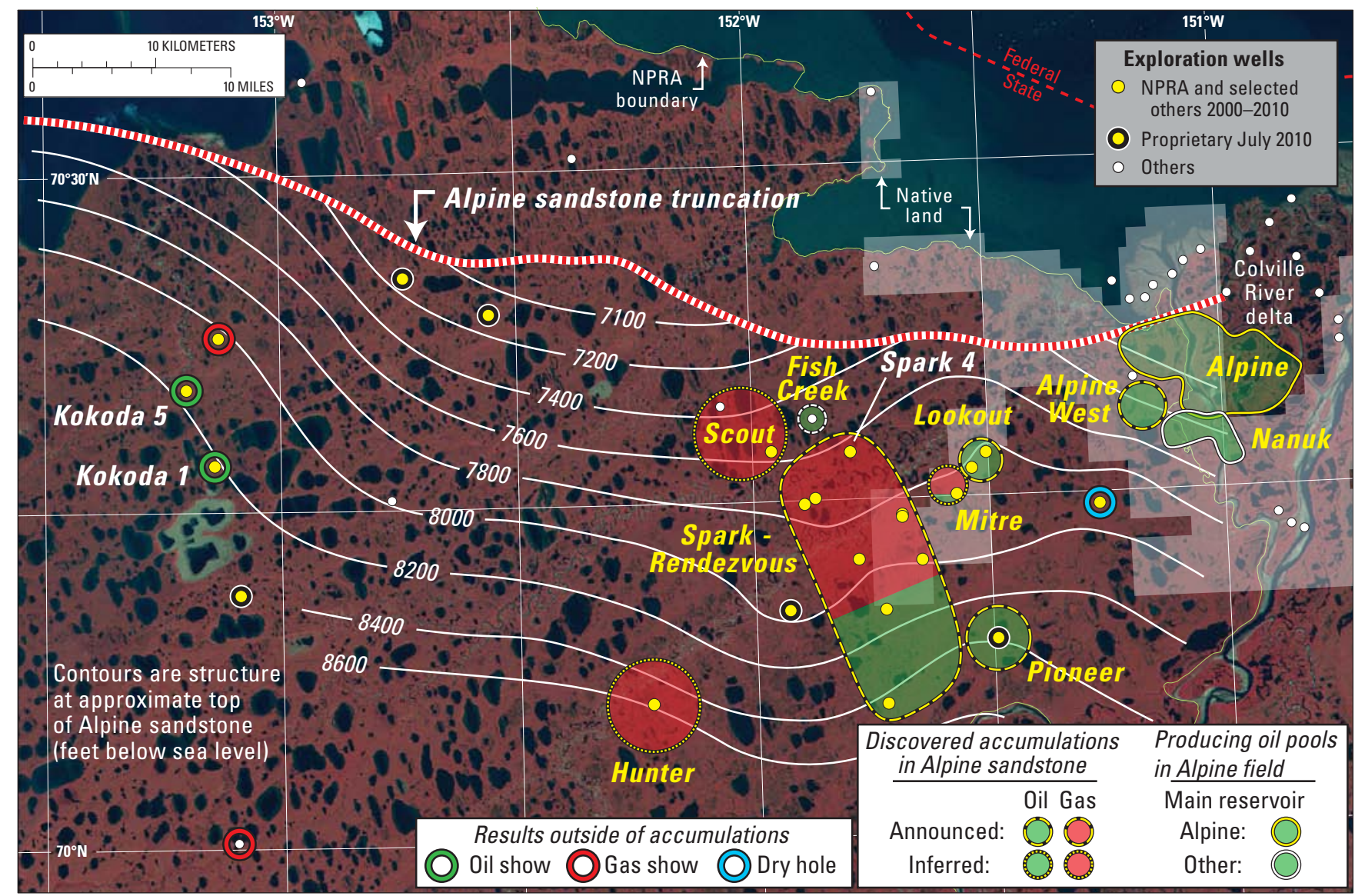

Figure 2. Northeastern NPRA and adjacent Colville River delta with locations of exploration wells within NPRA, selected wells outside NPRA, inferred oil and gas accumulations discovered in NPRA during 2000-2010 (yellow labels), and Native lands (white shading). Accumulations confirmed by public announcements of production tests are indicated by yellow dashed outlines; accumulations inferred from our analysis of public data are indicated by yellow dotted outlines. Pioneer has been confirmed by announcement of a production test even though no well data have been released. Specific exploration wells discussed in text are labeled in white. Alpine field oil pools that extend into NPRA and that produce from the Alpine sandstone and from other reservoirs are labeled "Alpine" and "Nanuk," respectively; these pools have been developed with numerous vertical and horizontal wells, which are not shown. The Alpine West accumulation has been confirmed by horizontal wells drilled from outside NPRA. No information is publicly available for the wells labeled by symbols indicating "proprietary." Fish Creek is a small oil accumulation in Brookian topsets discovered in 1949 and is considered subeconomic.

NPRA. Significantly, evidence of oil saturation in Brookian stratigraphic plays west of the oil-to-gas transition (fig. 2) suggests that Brookian rocks may have been shielded from these processes and may retain potential for undiscovered oil across northern NPRA.

\section{Results of Updated Assessment}

The updated 2010 assessment of NPRA used the same 24 plays and methodology as the 2002 assessment. Quantitative assessments were revised for 11 plays, and 9 of the 2002 plays are unchanged (table 1). Four plays were eliminated from quantitative assessment because results of recent drilling indicate that reservoir quality is insufficient for conventional petroleum accumulations (table 1); these have potential for unconventional resources - probably as "tight gas sandstone" plays.

Results of this 2010 updated assessment include total mean values for fully risked, undiscovered, technically recoverable resources in conventional accumulations of $896 \mathrm{MMBO}$ and
52,839 BCFG (nonassociated gas only). The sum of undiscovered oil resources (896 MMBO) plus liquids (oil and condensate) estimated to have been discovered during 2000-2010 (120 to $200 \mathrm{MMBO}$ ) is only about 10 percent of the total undiscovered oil estimated by the 2002 assessment (10,560 MMBO; table 1). This striking reduction reflects the results of exploration drilling, specifically (1) the unanticipated and abrupt transition from oil to gas just 15-20 miles west of the Alpine oil field and (2) poor reservoir quality in key formations.

The sum of undiscovered nonassociated gas resources $(52,839$ BCFG) plus gas resources estimated to have been discovered during 2000-2010 (1,900 to 3,000 BCFG) is approximately 90 percent of the total undiscovered nonassociated gas estimated by the 2002 assessment (61,352 BCFG; table 1). This slight reduction mostly reflects (1) the elimination of four gas-prone plays from quantitative assessment as conventional resources, (2) a substantial shift of resources from oil to gas in Beaufortian stratigraphic plays, and (3) a moderate shift 
Table 1. NPRA 2010 updated assessment results, including estimated volumes of fully risked, undiscovered, technically recoverable oil and nonassociated gas. Play-level results are color coded as follows: yellow, quantitative assessment revised in current assessment; blue, quantitative assessment not revised from 2002 results; tan, eliminated from quantitative assessment because the presence of reservoir quality sufficient for conventional petroleum accumulations is considered unlikely. For comparison, mean resource estimates from 2002 assessment are shown in gray columns at right. [MMB0, million barrels of oil; BCFG, billion cubic feet of gas; F95 represents a 95 -percent chance of at least the amount tabulated; other fractiles are defined similarly]

\begin{tabular}{|c|c|c|c|c|c|c|c|c|c|c|c|}
\hline & & \multicolumn{4}{|c|}{ OIL (MMBO) } & \multicolumn{4}{|c|}{ Nonassociated Gas (BCFG) } & \multicolumn{2}{|c|}{2002 Mean } \\
\hline & & F95 & \begin{tabular}{l|l} 
F50 \\
\end{tabular} & F05 & Mean & \begin{tabular}{l|l|} 
F95 & \\
\end{tabular} & \begin{tabular}{l|l} 
F50 & \\
\end{tabular} & \begin{tabular}{l|l|} 
F05 & \\
\end{tabular} & Mean & Oil* & Gas** \\
\hline \multirow{5}{*}{ 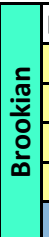 } & BROOKIAN STRATIGRAPHIC PLAYS & & & & & & & & & & \\
\hline & Brookian Topset & 21 & 107 & 249 & 117 & 0 & 300 & 1,079 & 386 & 239 & 192 \\
\hline & Brookian Clinoform North & 49 & 241 & 557 & 265 & 0 & 870 & 2,502 & 1,004 & 1,306 & 674 \\
\hline & Brookian Clinoform Central & 0 & 104 & 352 & 129 & 0 & 1,926 & 5,235 & 2,215 & 973 & 5,405 \\
\hline & Brookian Clinoform South-Shallow & 0 & 102 & 346 & 127 & 0 & 1,988 & 5,201 & 2,253 & 508 & 2,405 \\
\hline
\end{tabular}

\begin{tabular}{|c|c|c|c|c|c|c|c|c|c|c|c|c|}
\hline \multicolumn{12}{|c|}{ BEAUFORTIAN STRATIGRAPHIC PLAYS } & \\
\hline \multirow{6}{*}{ 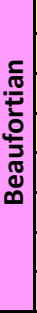 } & Beaufortian Cretaceous Topset North & 0 & 0 & 48 & 8 & 0 & 592 & 1,685 & 670 & 103 & 405 & \\
\hline & Beaufortian Upper Jurassic Topset NE & 0 & 26 & 80 & 33 & 829 & 2,415 & 5,254 & 2,638 & 5,176 & 2,130 & \\
\hline & Beaufortian Upper Jurassic Topset NW & 0 & 0 & 0 & 0 & 251 & 967 & 2,211 & 1,047 & 1,859 & 0 & : \\
\hline & Beaufortian Cretaceous Topset South & \multirow{3}{*}{\multicolumn{8}{|c|}{$\begin{array}{l}\text { The presence of reservoir quality sufficient for conventional accumulations is } \\
\text { considered unlikely based on recent drilling results in northern NPRA. }\end{array}$}} & 0 & 0 & 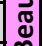 \\
\hline & Beaufortian Upper Jurassic Topset SE & & & & & & & & & 0 & 5,220 & \\
\hline & Beaufortian Upper Jurassic Topset SW & & & & & & & & & 0 & 793 & \\
\hline
\end{tabular}

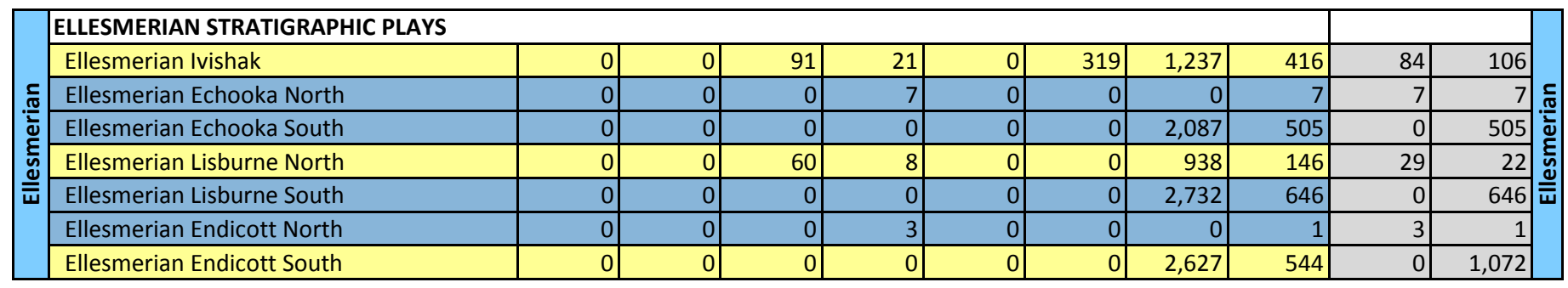

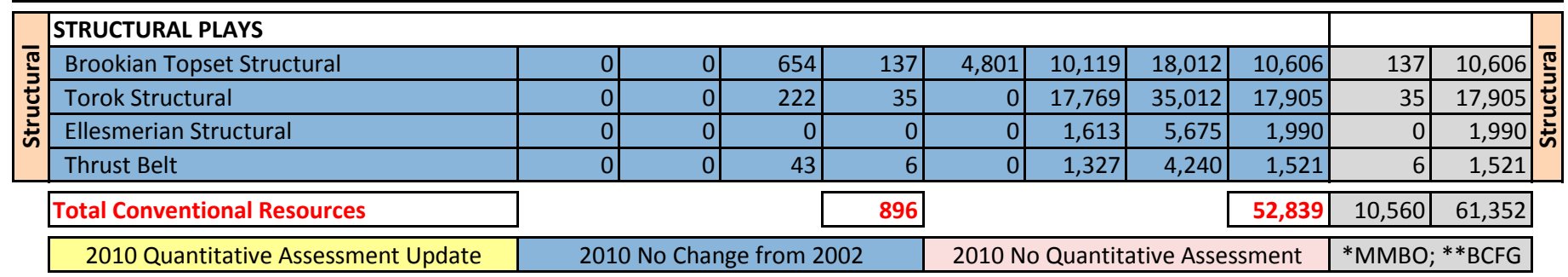

of resources from oil to gas in Brookian stratigraphic plays (table 1).

The results of the 2010 updated assessment indicate that the largest potential for undiscovered oil resources occurs in Brookian stratigraphic plays (table 1), which are widely distributed across NPRA. Beaufortian stratigraphic plays, which previously were considered to hold the greatest oil potential, are now thought to have limited undiscovered oil potential. The largest potential for undiscovered oil lies in northeastern NPRA, generally in the area estimated to have undergone less than 2,500 feet of Cenozoic uplift (fig. 1).

The largest potential for undiscovered nonassociated gas resources is in structural plays in southern NPRA. Also, significant potential for nonassociated gas resources is now shifted to Beaufortian and Brookian stratigraphic plays in northern NPRA, which previously were considered primarily oil-prone (table 1).

\section{For Further Information}

Supporting geological reports on the 2010 updated assessment of NPRA will be released as completed at http://energy. cr.usgs.gov/oilgas/noga.

Information regarding the 2002 USGS assessment of NPRA, including complete play descriptions and maps, is available at http://energy.usgs.gov/alaska/npra.html.

\section{NPRA Assessment Team:}

David W. Houseknecht (Project Chief; dhouse@usgs.gov), Kenneth J. Bird, John H. Schuenemeyer, Emil D. Attanasi, Christopher P. Garrity, Christopher J. Schenk, Ronald R. Charpentier, Richard M. Pollastro, Troy A. Cook, and Timothy R. Klett. 